The Early Career Section is a new community project, featured here in the Notices. This column will provide information and suggestions for graduate students, job seekers, junior academics of all types, and those who mentor them. Angela Gibney serves as the editor of this section. This month's theme is jobs in Business, Industry, and Government. Next month's theme will be Plan for a productive summer.

\title{
Transitioning from Academia to Industry? Here is some advice.
}

Carol E. Fan

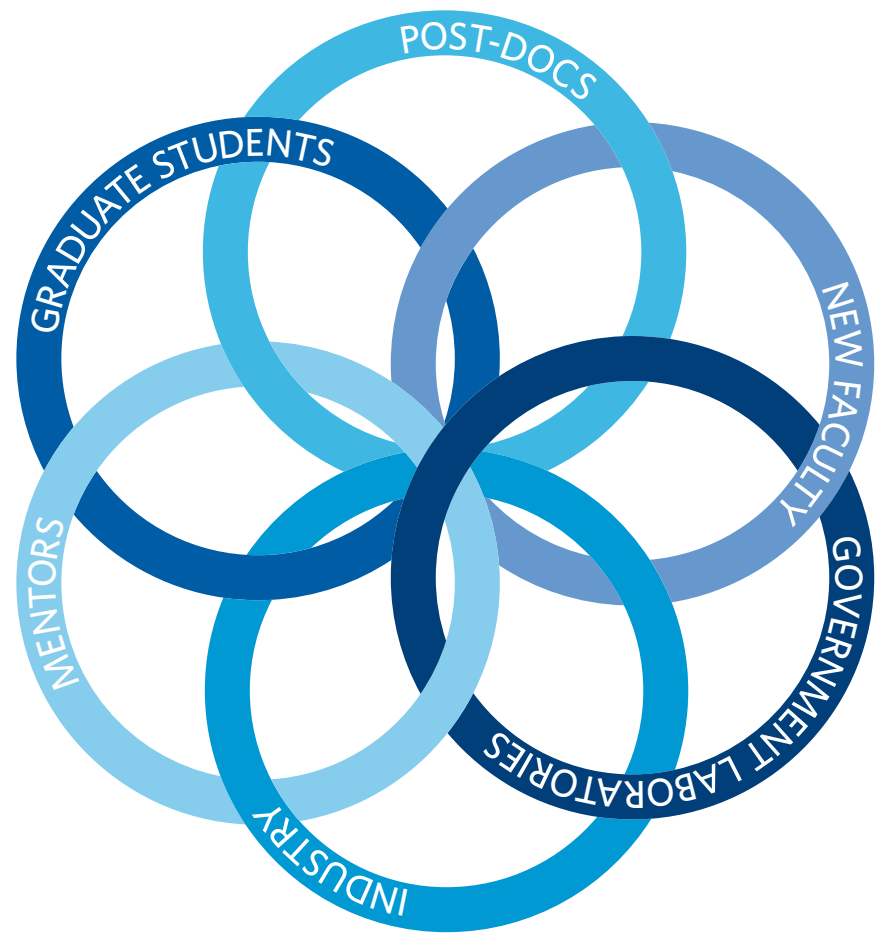

Carol E. Fan is Director of Data Science at Stellar Labs. Her email address is cefan_2000@gmai1.com.

For permission to reprint this article, please contact: reprint -permission@ams.org.

DOI: https://dx.doi.org/10.1090/noti 1863
Mathematicians are not always well understood by hiring managers within industry, particularly within Silicon Valley technology companies. Once you've made the decision to make the transition from academia to industry, here are a few things to keep in mind.

\section{First, identify the types of positions for which to apply.}

Within many technology companies, roles with titles such as "data analyst" or "data scientist" are a good place to start. People in these positions analyze data and produce recommendations. The techniques used in analyzing data can range from simple analysis of patterns and statistical tests of proportions, to non-linear optimization and neural networks. The recommendations can run the gamut from changing the color of a button on a webpage, to implementing an artificial intelligence algorithm that returns translated text in near real time.

The skills required for these roles vary from Excel macro building and SQL programming, to writing production-ready code that is ready for implementation in Python, R, or Java. Having a strong mathematical background facilitates quickly picking up new coding languages and domain knowledge. The vast majority of employers prefer that you have these skills in hand at the time of application; a few hiring managers may train you on the job, typically only for entry-level positions.

There are many types of problems that data analysts and data scientists work on. At a typical Silicon Valley company there is often a website and a product to sell to customers.

- Marketing analysts model the effectiveness of different marketing channels, e.g., direct mail or Facebook ads, in attracting paying customers. Optimizing digital marketing spending on social media platforms such as Facebook is a difficult and evolving problem to solve. 
- Product analysts improve a company's website or mobile app to ensure that customers can easily and intuitively purchase its product. The most effective companies are continually testing their website to make minor improvements in what is called an "agile" workflow.

- Operational analysts improve a company's ability to fulfill customer orders in a timely and cost-effective manner, often using operations research techniques such as optimization, queuing, network analysis, and inventory theory.

- Business intelligence (BI) analysts curate the source of truth for data and provide company-wide reporting for the purposes of better decision making. Their work is typically seen at the highest levels of the company.

\section{Second, signal to employers that you are the best person for the job.}

A typical job interview will consist of a technical test of coding skills. Sometimes "homework" will be assigned with a time limit. Then there will be several interviews with potential coworkers to assess whether or not your experience and skill set are a good match for the open position.

From the employer's point of view, there are two potential drawbacks to hiring academic mathematicians: lack of urgency and lack of business sense.

The stereotype of academics is that they will provide you with a solution to a problem only after they have thought through all of the possibilities, which could take weeks or months. Most businesses cannot wait that long. Make sure that you can provide examples of where you were able to complete an assignment in a short period of time and can explain what short cuts or trade-offs you would have taken if the deadline were one day versus one week away.

The more troublesome stereotype to dispel is the lack of business sense. At a business, all problems are seen through the lens of return on investment. How much effort is required to achieve the estimated benefit? If the decision is a minor one, a machine learning algorithm requiring months to validate and implement is unlikely to be necessary. Make sure that you can explain why you would choose one technique over another, given the time frame and potential benefit.

Aside from these two points, employers are typically looking for someone who can communicate. The person who can explain their methodology and findings to stakeholders from marketing to engineering, from the CEO to the warehouse worker, is highly valued.

\section{Finally, network, network, network.}

If you are making a transition, you are less likely to have connections in your new chosen area. Take advantage of alumni networks, friends of friends, and meet-ups-social networks such as LinkedIn and Facebook can introduce you to new contacts. Ask for an informational interview, or take someone to coffee. You just need one person to take a chance on you; it is up to you to find that person.

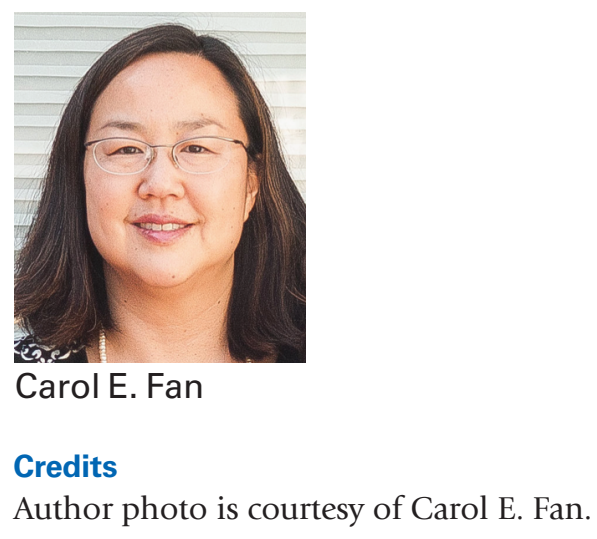

